\title{
A cyclic slip irreversibility based model for fatigue crack initiation of nickel base alloys
}

\author{
Hsin Shen $\mathrm{Ho}^{1,{ }^{*}}$, Marion Risbet ${ }^{2}$, and Xavier Feaugas ${ }^{3}$ \\ ${ }^{1}$ School of Mechanical Engineering, Zhengzhou University, 450001 Zhengzhou, China \\ ${ }^{2}$ UMR CNRS 7337, Université de Technologie de Compiègne, 60205 Compiegne cedex, France \\ ${ }^{3}$ UMR CNRS 7356, Université de La Rochelle, 17000 La Rochelle cedex, France
}

\begin{abstract}
The opportunity to define a microscopic law of fatigue crack initiation using Manson-Coffin law formulated in terms of cyclic slip irreversibility deduced from AFM measurements is discussed for a polycrystalline superalloy with different grain sizes and precipitate sizes. The results show that the modified Manson-Coffin law, relating cyclic slip irreversibility parameter to fatigue crack initiation life, is sustained through a two-parameter power law: $\varepsilon_{\mathrm{f}}^{\prime}$ and $\mathrm{c}$. The analysis suggests that the exponent c-value can be related to the degree of plastic strain incompatibility between grains, and the cumulative irreversible cyclic plastic strain to crack initiation is a relevant damage indicator for crack initiation. Consequently, our approach allows giving a physical base of engineering law.
\end{abstract}

\section{Introduction}

Fatigue damage of materials that exhibits flow localization is very often related to a surface phenomenon [1]. In these materials, the cyclic slip irreversibility, which is a phenomenon resulted from the slip displacements caused by the movement of dislocations in the forward part of the fatigue loading cycle that are not fully recovered in the reverse part of the fatigue loading cycle, is a primary source of fatigue crack initiation [2]. Cyclic slip irreversibility may arise from quite different physical mechanisms such as irreversible dislocation displacements resulted from cutting of precipitates and surface roughening caused by to-and-fro glide of dislocations, as recapitulated in Refs. [3-4]. Some other important factors known to promote cyclic slip irreversibility are the local microstructure and environment [5-6].

Cyclic slip irreversibility is difficult to be analyzed quantitatively [7]. Thereby, there exist many different forms of characterizing the cyclic slip irreversibility in which they are given numerical values, as summarized in Ref. [3]. Though, the cyclic slip irreversibility defined as the fraction of microstructurally irreversible cyclic plastic strain with respect to the total cyclic plastic strain is found to be one of the most relevant microstructural and life-determining fatigue damage parameter [7-8]. Some works have recently demonstrated the opportunity to use atomic force microscopy to measure slip band emergence and consequently the degree of reversibility during cyclic loading $[3,5,8]$. In low-cycle fatigue tests, a global and generic cumulative damage rule known as the Manson-Coffin (MC) law is generally used to express the relationship between total fatigue life and plastic strain amplitude [9-10]. Thereby, three questions arise: (i) whether the MC law can be formulated in terms of cyclic slip irreversibility, (ii) is the MC law changing if the early stage of damage is considered as fatigue crack initiation life, and (iii) what are the factors that influence the correlation between the two empirical parameters (ductility coefficient and power exponential value) dominating the microscopic law of fatigue crack initiation?

Thus, the aims of the present paper are firstly, to test the validity of $\mathrm{MC}$ rule formulated in terms of cyclic slip irreversibility for fatigue crack initiation of a Nibase superalloy with different grain sizes and precipitate sizes, where cyclic slip irreversibility is a result of repeated irreversible cutting of the coherent $\gamma^{\prime}$ precipitate particle during cycling, and secondly, to understand the nature and/or physical content of the two empirical parameters of the modified MC rule.

\section{Material and methods}

\subsection{Material}

The target material is a Ni-base superalloy (Waspaloy) strengthened by spherical precipitates $\left(\gamma^{\prime}, \mathrm{Ni}_{3} \mathrm{Al}\right)$, with the following chemical composition (wt.\%): $1.80 \mathrm{Al}$; $3.33 \mathrm{Ti} ; 12.64 \mathrm{Co} ; 19.45 \mathrm{Cr} ; 7.31 \mathrm{Mo}$; balance Ni. The average grain size $(D)$ and the average precipitate size (d) of the as-received state of Waspaloy are $64 \mu \mathrm{m}$ and $42 \mathrm{~nm}$, respectively. A two-step heat treatment (solutionizing and aging treatments) is carried out on the as-received state to modify $D$ and $d$ so as to obtain specimens with well-controlled metallurgical states, i.e.

Corresponding author: hsinshen.ho@,zzu.edu.cn 
different grain sizes of the matrix $\gamma$ with a constant $\gamma^{\prime}$ precipitate size and inversely (see Ref. [5] for details on heat treatment steps). In the present study, eight classes of specimens are selected with the following average grain size $(D)$ and average precipitate size $(d):(30 \mu \mathrm{m}, 7$ $\mathrm{nm}) ;(50 \mu \mathrm{m}, 10 \mathrm{~nm}) ;(50 \mu \mathrm{m}, 20 \mathrm{~nm}) ;(50 \mu \mathrm{m}, 30 \mathrm{~nm})$; $(50 \mu \mathrm{m}, 40 \mathrm{~nm}) ;(100 \mu \mathrm{m}, 10 \mathrm{~nm}) ;(100 \mu \mathrm{m}, 20 \mathrm{~nm})$ and $(200 \mu \mathrm{m}, 20 \mathrm{~nm})(c . f$. Table 1 indicating the stereological elements, e.g. grain size $(D)$ and precipitate size $(d)$, but also the values of the other parameters, e.g. fatigue crack initiation life $\left(N_{\mathrm{i}}\right)$, mean extrusion height $(\langle h\rangle)$, band thickness $(w)$ and mean inter-band spacing $\left(I_{\mathrm{B}}\right)$, of the specimens tested at three different levels of plastic strain amplitude $\left.\left(\varepsilon_{p}\right)\right)$.

\subsection{Methods}

The specimens are mechanically polished, then chemically-etched using standard metallographic techniques, as detailed in Ref. [5].

Interrupted low-cycle fatigue tests are conducted at ambient temperature using an Instron servohydraulic machine on hourglass-shaped cylindrical specimens. The fatigue tests are performed on controlled plastic strain amplitude $\left(\varepsilon_{p}\right)$ of $0.05 \%, 0.3 \%$ and $0.9 \%$ with a fully reversed triangular wave form at a frequency of $0.05 \mathrm{~Hz}$ until the nucleation of first cracks. Cracks are considered as nucleated when the length of a crack is equivalent to the dimension of a grain.
During fatigue testing, the fatigue hysteresis loops are recorded in order to track the cyclic behavior and to calculate the internal stresses. The cyclic stress amplitude $\left(\sigma_{\mathrm{a}}\right)$ is composed of effective stress $\left(\sigma_{\text {eff }}\right)$ and backstress $(X)$. The backstress $(X)$, which is to be discussed further, can thus be expressed as:

$$
X=\sigma_{\mathrm{a}}-\sigma_{\text {eff }} \text { with } \sigma_{\text {eff }}=\frac{1}{2}\left(\sigma_{\mathrm{a}}-\sigma_{\mathrm{r}}\right)+\frac{1}{2} \sigma^{*}
$$

where $\sigma^{*}$ is the thermal part of the flow stress and $\sigma_{\mathrm{r}}$ denotes the reverse yield stress, which are measured from the experimental hysteresis loops with a plastic strain offset of $(4 \pm 2) \times 10^{-5}$.

The surface states are characterized by scanning electron microscope (SEM) and atomic force microscope (AFM), using respectively a (FEG) Zeiss Sigma SEM and a Veeco Dimension 3100 AFM at room temperature. For each specimen, about 8 damaged grains and 8 undamaged grains are investigated. And for each grain, a few regions of $10 \mu \mathrm{m} \times 10 \mu \mathrm{m}$ are examined. Each region extracted using the topography-imaging mode contains around 20 slip bands. The surface roughness, representing the arisen surface marking from material surface, is then analyzed using the experimental procedure developed in Refs. [5,8]. In addition to the surface analysis, the bulk material is examined at room temperature using JEOL JEM2011 transmission electron microscope (TEM) operating at $200 \mathrm{kV}$.

Table 1. Metallurgical states of investigated specimens.

\begin{tabular}{|c|c|c|c|c|c|c|}
\hline $\begin{array}{c}\text { Plastic strain } \\
\text { amplitude } \\
\left(\varepsilon_{p}\right) \\
\end{array}$ & $\begin{array}{c}\text { Grain size } \\
(D, \mu \mathrm{m})\end{array}$ & $\begin{array}{c}\text { Precipitate } \\
\text { size } \\
(d, \mathrm{~nm})\end{array}$ & $\begin{array}{l}\text { Fatigue crack } \\
\text { initiation life } \\
\left(N_{i}, \text { cycle }\right)\end{array}$ & $\begin{array}{c}\text { Mean } \\
\text { extrusion } \\
\text { height } \\
(\langle h\rangle, \mathrm{nm})\end{array}$ & $\begin{array}{c}\text { Band } \\
\text { thickness } \\
(w, \mathrm{~nm})\end{array}$ & $\begin{array}{c}\text { Mean inter- } \\
\text { band spacing } \\
\left(I_{B}, \mu \mathrm{m}\right)\end{array}$ \\
\hline 0.0005 & 30 & 7 & 33500 & 50 & 80 & 8 \\
\hline \multirow[t]{7}{*}{0.003} & 30 & 7 & 1500 & 50 & 80 & 2.5 \\
\hline & 50 & 10 & 1100 & 98 & 121 & 1.75 \\
\hline & 50 & 20 & 800 & 107 & 140 & 2.17 \\
\hline & 50 & 30 & 700 & 109 & 146 & 1.93 \\
\hline & 50 & 40 & 650 & 116 & 171 & 2.42 \\
\hline & 100 & 10 & 950 & 97 & 130 & 1.7 \\
\hline & 100 & 20 & 700 & 98 & 150 & 2.11 \\
\hline \multirow[t]{3}{*}{0.009} & 30 & 7 & 320 & 50 & 80 & 1.0 \\
\hline & 50 & 40 & 65 & 40 & & 1.5 \\
\hline & 100 & 10 & 196 & 69 & & 0.8 \\
\hline
\end{tabular}




\section{Microstructure-based reformulation of the Manson-Coffin fatigue crack initiation life}

If the Manson-Coffin-type law is assumed to be valid for damage initiation in polycrystals Waspaloy, this law relates the plastic strain amplitude $\left(\varepsilon_{\mathrm{p}}\right)$ to the cycle number of crack initiation $\left(N_{\mathrm{i}}\right)$ through a two-parameter power law [9-10]:

$$
\varepsilon_{\mathrm{p}}=\varepsilon_{\mathrm{f}}^{\prime}\left(2 N_{\mathrm{i}}\right)^{c}
$$

where $\varepsilon_{\mathrm{f}}^{\prime}$ and $c(<0)$ are the fatigue ductility coefficient and exponent, respectively.

Inspired by earlier works of Mughrabi and Risbet et al., which propose to formulate a life law in terms of microstructural parameters instead of the function of macroscopic plastic strain amplitude endured by the specimen during fatigue test, the plastic strain irreversibility ( $\left.p_{\text {irr }}^{\text {cum }}\right)$ is introduced in the present work as a microstructural parameter to explicitly take into account the fatigue damage resulted from irreversible plastic strain $[7-8,11]$. The parameter $p_{\text {irr }}^{\text {cum }}$ is defined as the fraction of the microstructurally irreversible cyclic plastic strain with respect to the total cyclic plastic strain.

$$
p_{\text {irr }}^{\text {cum }}=\frac{\gamma_{\text {irr,pl,loc }}^{\text {cum }}}{\gamma_{\text {pl,loc }}^{\text {cum }}}
$$

where $\gamma_{\text {irr,pl,loc }}^{\text {cum }}$ is the cumulative irreversible cyclic plastic strain, expressed as:

$$
\gamma_{\text {irr,pl,loc }}^{\text {cum }}=\frac{h}{D}
$$

where $h$ is the mean extrusion height and $D$ is the average grain size, and $\gamma_{\mathrm{pl} \text {, loc }}^{\mathrm{cum}}$ is the local plastic strain, representing the total plastic strain accumulated in a slip band during $N$ fatigue cycles. $\gamma_{\mathrm{pl}, \mathrm{coc}}^{\mathrm{cum}}$ is expressed as a function of the volume fraction of slip bands $\left(f_{v}\right)$, which itself depends on inter-band spacing $\left(I_{B}\right)$ and volume fraction of one slip band $\left(f_{1}\right)$ :

$$
\begin{aligned}
\gamma_{\mathrm{pl}, \mathrm{loc}}^{\text {cum }}=\sum_{\mathrm{k}=1}^{\mathrm{N}} \gamma_{\mathrm{pl}, \mathrm{loc}} & =\left(\sum_{\mathrm{k}=1}^{\mathrm{N}} I_{\mathrm{B}}\left(N, \varepsilon_{\mathrm{p}}\right)\right) \frac{4 M \varepsilon_{\mathrm{p}}}{D f_{1}} \\
& =\gamma_{\mathrm{pl}, \mathrm{loc}}^{\text {cum }}\left(N, \varepsilon_{\mathrm{p}}\right)
\end{aligned}
$$

where $M$ is the Taylor factor and $N$ is the number of cycles. In shearable-precipitated alloy, the plastic strain is supported by multiplication of slip bands, and thus $I_{B}$ is dependent on $\varepsilon_{p}$. By combining the expressions for $\gamma_{\text {irr,pl,loc }}^{\text {cum }}$ in Eq. (4) and $\gamma_{\text {pl,loc }}^{\text {cum }}$ in Eq. (5), $p_{\text {irr }}^{\text {cum can be }}$ expressed as a function of $N$ :

$$
p_{\text {irr }}^{\text {cum }}=\frac{h f_{1}}{N I_{\mathrm{B}}\left(N_{\mathrm{i}}, \varepsilon_{\mathrm{p}}\right) \varepsilon_{\mathrm{p}} 4 M}=p_{\text {irr }}^{\text {cum }}\left(N, \varepsilon_{\mathrm{p}}\right)
$$

\section{Experimental validations}

\subsection{Empirical relationship between plastic strain irreversibility and fatigue crack initiation life}

Fig. 1. Variation of the fraction of the microstructurally irreversible cyclic plastic strain $\left(p_{\text {irr }}^{\text {cum }}\right)$ as a function of the number of cycles $\left(N_{\mathrm{i}}\right)$ for different metallurgical states tested under three different levels of plastic strain amplitude $\left(\varepsilon_{p}\right)$.

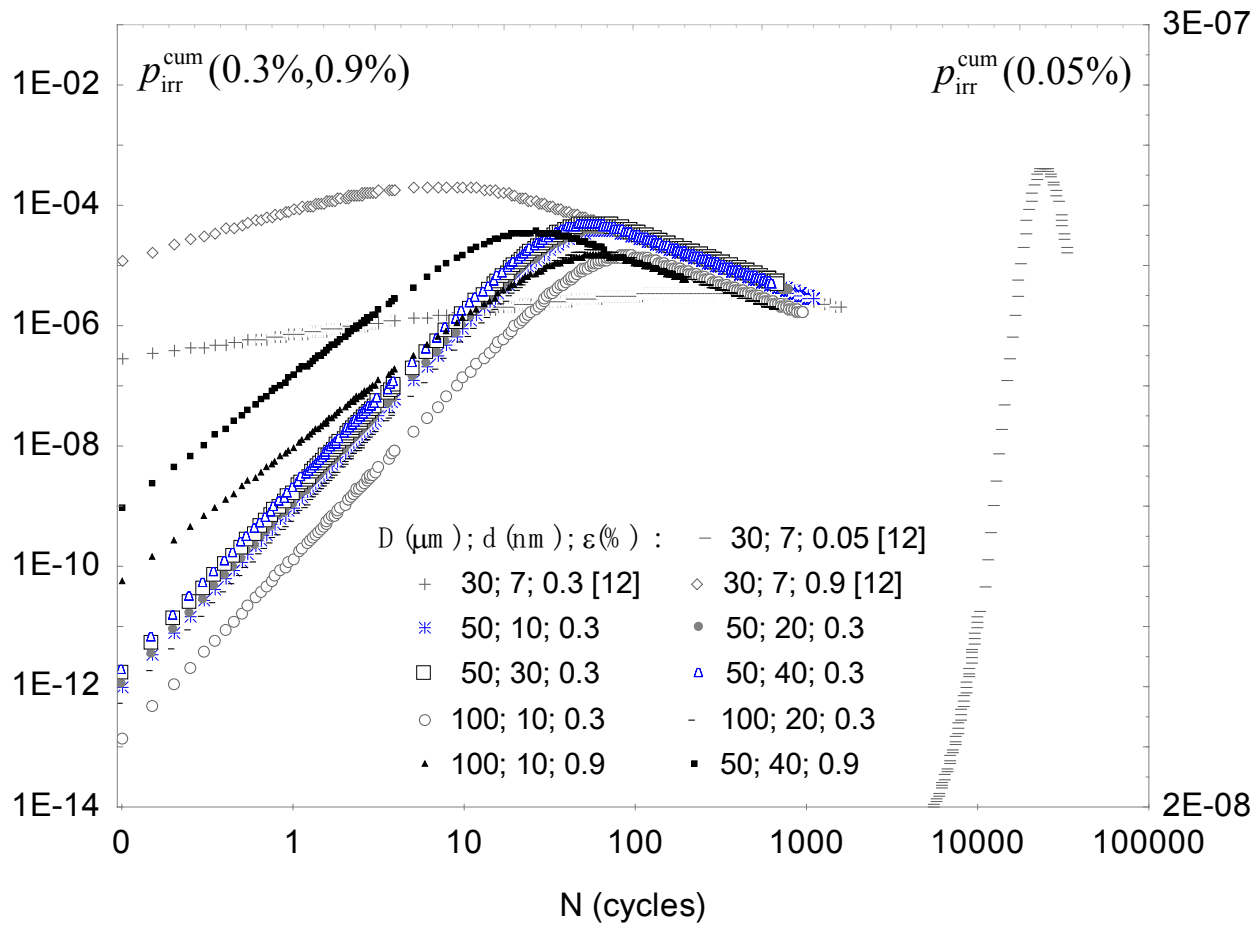


Eq. (6) shows that $p_{\text {irr }}^{\text {cum }}$ is dependent on $N$ and our results reveal that $p_{\text {irr }}^{\text {cum }}$ first increases and then decreases with increasing $N$, as exhibited in Fig. 1. Figure 1 shows that the functional dependency between $p_{\text {irr }}^{\text {cum }}$ and $N$ remains valid for all the specimens investigated in the present study, in coherence with earlier results obtained with the same alloy of only one metallurgical state tested under three different levels of plastic strain $\varepsilon_{p}$ [8].

At the fatigue crack initiation phase $\left(N=N_{\mathrm{i}}\right)$, $p_{\text {irr }}^{\text {cum }}\left(N_{\mathrm{i}}\right)$ is found to be dependent on $\varepsilon_{\mathrm{p}}$ (and hence also on $N_{\mathrm{i}}$ ), as is exhibited in Fig. 2. It is shown in this figure that $p_{\text {irr }}^{\text {cum }}\left(N_{\mathrm{i}}\right)$ increases when $\varepsilon_{\mathrm{p}}$ increases (or when $N_{\mathrm{i}}$ decreases). The variation of $p_{\text {irr }}^{\text {cum }}\left(N_{\mathrm{i}}\right)$ with $\varepsilon_{\mathrm{p}}$ (and $\left.N_{\mathrm{i}}\right)$ fits well with the results reported in the literature [8].

Fig. 2. Variation of plastic strain irreversibility $\left(p_{\text {irr }}^{\text {cum }}\left(N_{i}\right)\right)$ as a function of plastic strain amplitude $\left(\varepsilon_{p}\right)$ for different grain sizes (D).

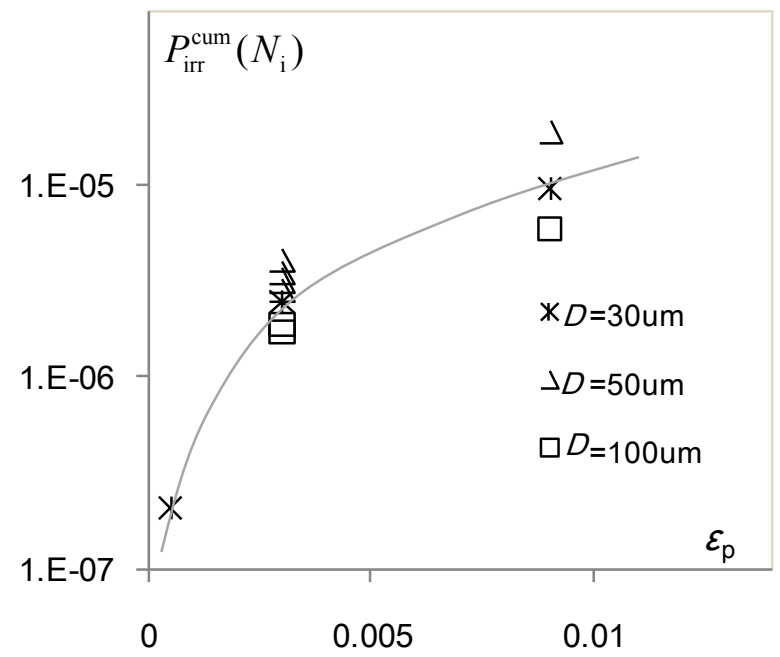

The Manson-Coffin relation in Eq. (2) formulated in terms of cyclic slip irreversibility for $N=N_{i}$ expressed in Eq. (6) can be rewritten in modified form as:

$$
\begin{aligned}
p_{\text {irr }}^{\text {cum }}\left(N_{\mathrm{i}}\right) I_{\mathrm{B}}\left(N_{\mathrm{i}}\right) D & =\frac{\langle h\rangle f_{1} D}{2^{c+1} 2 M \varepsilon_{\mathrm{f}}^{\prime}} \times N_{\mathrm{i}}^{-(c+1)} \\
& =\text { constant } \times N_{\mathrm{i}}^{-(c+1)}
\end{aligned}
$$

Eq. (7) implies that the product $p_{\text {irr }}^{\text {cum }}\left(N_{\mathrm{i}}\right) I_{\mathrm{B}}\left(N_{\mathrm{i}}\right) D$ is linked with the fatigue crack initiation life $\left(N_{i}\right)$ in a welldefined manner. Thereby, the variations of the product $p_{\text {irr }}^{\text {cum }}\left(N_{\mathrm{i}}\right) I_{\mathrm{B}}\left(N_{\mathrm{i}}\right) D$ with $N_{i}$ determined experimentally from AFM observations are assessed for three different grain sizes. In Fig. 3, the following expressions are found:

$$
\begin{aligned}
p_{\text {irr }}^{\text {cum }}\left(N_{\mathrm{i}}\right) I_{\mathrm{B}}\left(N_{\mathrm{i}}\right) D & =3 \times 10^{-15} N_{i}^{-0.38}, \\
\text { for } D & \approx 30 \mu \mathrm{m} \\
p_{\text {irr }}^{\text {cum }}\left(N_{\mathrm{i}}\right) I_{\mathrm{B}}\left(N_{\mathrm{i}}\right) D & =2 \times 10^{-14} N_{i}^{-0.57}, \\
\text { for } D & \approx 50 \mu \mathrm{m} \\
p_{\text {irr }}^{\operatorname{cum}}\left(N_{\mathrm{i}}\right) I_{\mathrm{B}}\left(N_{\mathrm{i}}\right) D & =2 \times 10^{-15} N_{i}^{-0.25},
\end{aligned}
$$

$$
\text { for } D \approx 100 \mu \mathrm{m}
$$

Fig. 3. Evolution of the product $p_{\mathrm{irr}}^{\text {cum }}\left(N_{\mathrm{i}}\right) I_{\mathrm{B}}\left(N_{\mathrm{i}}\right) D$ with cycle number to crack initiation $\left(N_{i}\right)$.

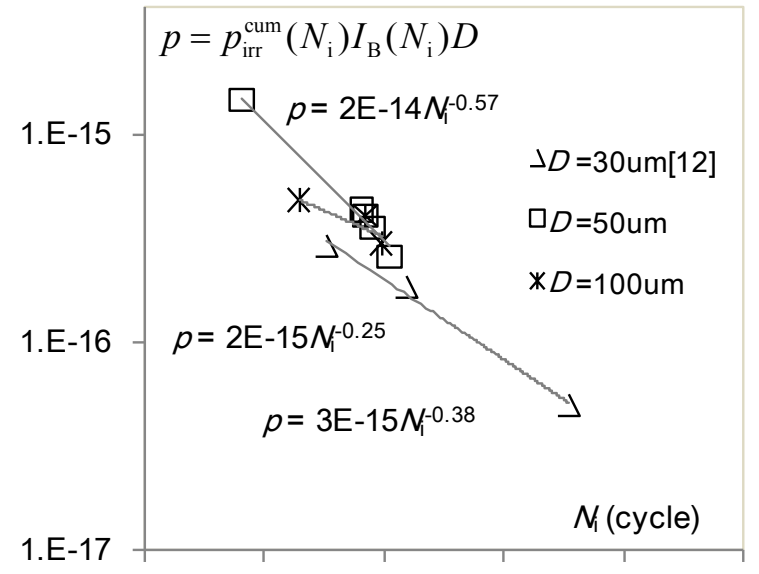

$1 . E+1 \quad 1 . E+2 \quad 1 . E+3 \quad 1 . E+4 \quad 1 . E+5 \quad 1 . E+6$

The data plotted in Fig. 3 and the relationships shown in Eqs. (8) - (10) suggest that the product $p_{\text {irr }}^{\text {cum }}\left(N_{\mathrm{i}}\right) I_{\mathrm{B}}\left(N_{\mathrm{i}}\right) D$ is empirically connected to the fatigue crack initiation life $\left(N_{i}\right)$ by a power law in the form of:

$$
p \approx \alpha\left(2 N_{i}\right)^{-\beta}
$$

Eq. (11) seems to be rather similar to Eq. (7). Thus, from a comparison of Eqs. (7) and (11), it follows that:

$$
p=p_{\text {irr }}^{\text {cum }}\left(N_{\mathrm{i}}\right) I_{\mathrm{B}}\left(N_{\mathrm{i}}\right) D
$$

and

$$
\alpha=\frac{\langle h\rangle f_{1} D}{2^{c+1} 2 M \varepsilon_{\mathrm{f}}^{\prime}}=\text { constant }
$$

and

$$
\beta=c+1
$$

Morrow has suggested that for total fatigue life, $c$ is ranging from -0.5 to -0.6 [12]. Yet, lower $c$-values are found for fatigue crack initiation life [13]. Thereby, the exponents $\beta$ in Eqs. (8) - (10) are examined to verify if they are reasonably connected to $c+1$. With the data obtained from the literature, one expects that $\beta=c+1<$ 0.5 for the early-stage fatigue damage. Within the limit, the exponents $\beta$ in Eqs. (8) - (10), found to be equivalent to 0.38 for $D \approx 30 \mu \mathrm{m}, 0.57$ for $D \approx 50 \mu \mathrm{m}$ and 0.25 for $D \approx 100 \mu \mathrm{m}$, are in fairly good agreement with expectation.

\subsection{Correlation between fatigue ductility coefficient and fatigue ductility exponent}

Subsequently, the two coefficients of the Manson-Coffin fatigue crack initiation law denoted as $\varepsilon_{\mathrm{f}}^{\prime}$ and $c$ are deduced from Eqs. (13) - (14) by considering the following experimental data: $\langle h\rangle=100 \times 10^{-9} \mathrm{~m}, f_{1}=3.3$ $\times 10^{-3}(D \approx 30 \mu \mathrm{m})$ or $f_{1}=2.0 \times 10^{-3}(D \approx 50 \mu \mathrm{m})$ or $f_{1}=$ $1.0 \times 10^{-3}(D \approx 100 \mu \mathrm{m})$, and $M=3$. The relationship 
between the two empirical parameters of MC law are further assessed.

In the literature, it is shown by correlation that $\varepsilon_{\mathrm{f}}^{\prime}$ and $c$ can be connected through a linear $\log \left(\varepsilon_{\mathrm{f}}^{\prime}\right)-c$ relationship [13]. Thus, an $\log \left(\varepsilon_{\mathrm{f}}^{\prime}\right)=\log \left(\varepsilon_{\mathrm{p}}^{\prime}\right)-c \log$ $\left(2 N_{\mathrm{i}}^{\prime}\right)$ type correlation between $\varepsilon_{\mathrm{f}}^{\prime}$ and $c$ is assessed (c.f. Fig. 4); the coefficients $\varepsilon_{\mathrm{p}}^{\prime}$ and $N_{\mathrm{i}}^{\prime}$, reported to be the coordinates of a fixed point at varying $c$, would have potential to be related to the fatigue damage [14]. Fig. 4 exhibits that the $\log \left(\varepsilon_{\mathrm{f}}^{\prime}\right)$ value is decreasing with increasing $c$-value, implying that the supposed correlation between the logarithm of $\varepsilon_{\mathrm{f}}^{\prime}$ and $c$ is rather strong. Finally, with the correlation coefficient value $(R)$ of 0.948 , the correlation can be regarded to be rather viable.

Fig. 4. Correlation between log fatigue ductility coefficient $\left(\varepsilon_{f}^{\prime}\right)$ $v s$. fatigue ductility exponent $(c)$.

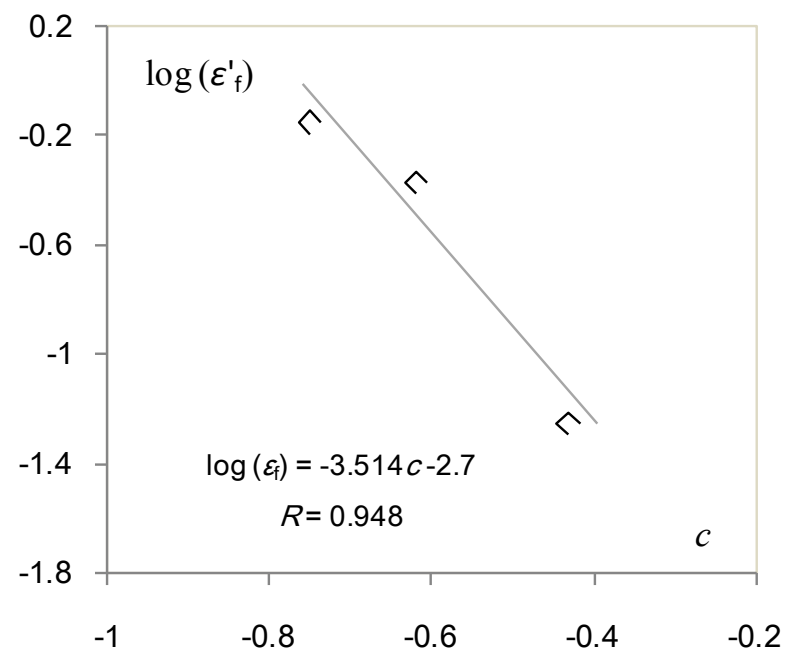

In an attempt to examine the factors influencing the correlation between $\varepsilon_{\mathrm{f}}^{\prime}$ and $c$ plotted in Fig. 4, the behavior of the fatigue ductility exponent $(c)$ is assessed as a function of the grain size $(D)$ for fatigue damage initiation in polycrystal Waspaloy. Our results show that $c$ exhibits a decreasing tendency with increasing $D$. Thus, to understand the behavior of $c v s$. $D$, an approach based on an overall analysis of the impact of internal stresses on the occurrence of early fatigue damage is used in the following. It is worth noting that the initiation of cracks along slip bands is very often argued to be a consequence of the local stress concentration due to strain localization [11]. Thereby, to explore the possible contribution of the stress-strain relationship on the crack initiation process, the average value of the long-range internal stress (backstress $X$ ) estimated at the crack initiation phase is examined.

According to Feaugas et al., the backstress $(X)$ stemming from the long-range interaction can be decomposed into two distinct components called intragranular backstress $\left(X_{\text {intra }}\right)$ and intergranular backstress $\left(X_{\text {inter }}\right)$ :

$$
X=X_{\text {intra }}+X_{\text {inter }}
$$

where $X_{\text {intra }}$ is related to strain incompatibility between grains, which involves the crystal or grain boundary structure, while $X_{\text {inter }}$ is a consequence of the heterogeneity of the dislocation spatial distribution [15]. The results show that the backstress $(X)$ is inversely proportional to the grain size $(D)$. Our analyses then show that the dependency of the backstress $(X)$ on the grain size $(D)$ is mainly related to the intergranular longrange internal stresses $\left(X_{\text {inter }}\right)$ created by the plastic strain incompatibility between grains, in agreement with previous results reported in the literature [16]. In Fig. 5, $X_{\text {inter }}$ is found to be a decreasing function of the grain size $D$ and thus, the functional relationship between $X_{\text {inter }}$ and $D$ can be formalized using the following phenomenological law with $D$ in micrometers:

$$
X_{\text {inter }}=920 \times D^{-1 / 2}
$$

This finding suggests that the elastic-energy stored inside the slip bands can easily be relaxed when the grain size increases due to the decrease in the plastic strain incompatibility resulting from the slip transmission across the grain boundary, which implies that the grain of large-grain-sized polycrystals can be considered as pseudo-monocrystal.

Fig. 5. Evolution of intergranular long-range internal stresses $\left(X_{\text {inter }}\right)$ as a function of grain size $(D)$.

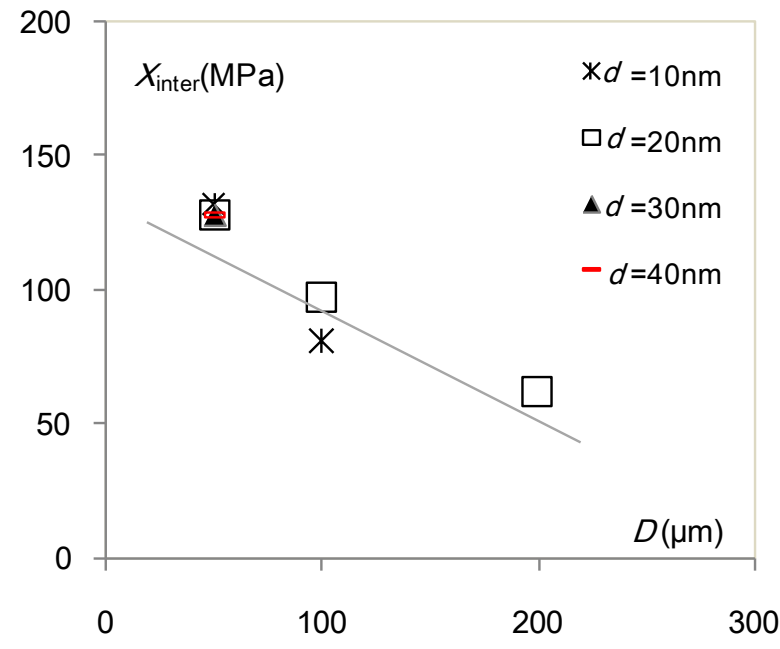

\subsection{The cumulative irreversible cyclic plastic strain to fatigue crack initiation}

Ho et al. showed that there exists a critical value of cumulative irreversible cyclic plastic strain to crack initiation $\left(\gamma_{\text {irr,pl,loc }}^{\text {cum }}\right)$ for fatigued polycrystal Waspaloy and they found that fatigue damage is initiated when $\gamma_{\text {irr,pl,loc }}^{\text {cum }}$ is equal to $1.3 \pm 0.3 \times 10^{-3}$ [5]. It is therefore important to evaluate this quantity based on the modified MansonCoffin fatigue crack initiation law in Eq. (7). Rewriting Eq. (4) by considering Eq. (13), we obtain:

$$
\gamma_{\mathrm{irr}, \mathrm{pl}, \mathrm{loc}}^{\mathrm{cum}}=\frac{\alpha 2 M \varepsilon_{f}^{\prime} 2^{c+1}}{D^{2} f_{1}}
$$


Evaluation of a critical cumulative irreversible cyclic plastic strain to crack initiation $\left(\gamma_{\text {irr,pl,loc }}^{\text {cum }}\right)$ via Eq. (17) for the grain sizes of $30 \mu \mathrm{m}, 50 \mu \mathrm{m}$ and $100 \mu \mathrm{m}$ yields very similar values of $3.3 \times 10^{-3}, 2.0 \times 10^{-3}$ and $1.0 \times 10^{-3}$, respectively. They are of the same order of magnitude as the critical value of $1.3 \pm 0.3 \times 10^{-3}$ computed directly from Eq. (4). However, the critical value of cumulative irreversible cyclic plastic strain to crack initiation for fatigued polycrystals Waspaloy is found to be much smaller than the critical value of cumulative irreversible cyclic plastic strain to failure, estimated to lie in the range of $\sim 10$ to $\sim 30$, for fatigued $\alpha$-iron polycrystals and $\mathrm{Cu}-31 \% \mathrm{Zn}$ ( $\alpha$-brass) single crystal [4]. In this sense, it can be expected that the characteristic critical value of cumulative irreversible cyclic plastic strain for a specific damage type in a particular material is rather unique, as assumed by the modified Manson-Coffin fatigue crack initiation law [5]. Thereby, the computed critical value of cumulative irreversible cyclic plastic strain equal to $1.3 \pm 0.3 \times 10^{-3}$ can thus be considered as a constant for the early stages of fatigue damage in polycrystal Waspaloy.

\section{Conclusions}

In summary, a microstructure-based reformulation of the modified Manson-Coffin law has been discussed for fatigued Ni-based superalloy, Waspaloy. The experimental results suggest the existence of a powerlaw relationship between cyclic slip irreversibility parameter and fatigue crack initiation life, and show that the two-parameter of the Manson-Coffin law can be related through a linear $\log \left(\varepsilon_{\mathrm{f}}^{\prime}\right)-c$ relationship. The analyses suggest that higher exponent $c$-value signifies higher sensitivity to the plastic strain incompatibility between grains and that fatigue crack initiation life can be controlled by limiting the value of cumulative irreversible cyclic plastic strain to crack initiation.

\section{References}

1. S. Suresh, Fatigue of Materials. second ed., Cambridge University Press, Cambridge (1998)

2. U. Essmann, U. Gosele U, H. Mughrabi, Philos. Mag. A 44, 405-426 (1981)

3. A. Shyam, W.W. Milligan, Acta Mater. 53, 835-844 (2005)

4. H. Mughrabi, Acta Mater. 61, 1197-1203 (2013)

5. H.S. Ho, M. Risbet, X. Feaugas, Scr. Mater. 65, 998-1001 (2011)

6. P. Zhang, Z.J. Zhang, L.L. Li, Z.F. Zhang, Scr. Mater. 66, 854-859 (2012)

7. H. Mughrabi, Metall. Mater. Trans. A 40, 12571279 (2009)

8. M. Risbet, X. Feaugas, Scr. Mater. 49, 533-538 (2003)

9. L.F. Coffin, Trans. ASME 76, 931-950 (1954)

10. S.S. Manson, NACA Rep. 1170, 317-350 (1954)
11. M. Risbet, X. Feaugas, Eng. Fract. Mech. 75, 35113519 (2008)

12. J.D. Morrow, ASTM STP 378. Philadelphia, PA: ASTM (1965)

13. H. Alush, Y. Katz, M.B. Maros, L. Toth, J Mater. Process. Technol. 157-158, 16-22 (2004)

14. B. Tribonod, Int. J Fatigue 81, 143-147 (2015)

15. X. Feaugas, H. Haddou, Metall. Mater. Trans. A 34, 2329-2340 (2003)

16. X. Feaugas, Acta Mater. 47, 3617-3632 (1999) 